\title{
8 FOOLING AROUND: The Corporate Jester as an Effective Change Agent for Technological Innovation
}

\author{
Tom McMaster \\ University of Salford \\ Salford, United Kingdom \\ David Wastell \\ University of Manchester and \\ Nottingham Business School \\ United Kingdom \\ Helle Zinner Henriksen \\ Copenhagen Business School \\ Copenhagen, Denmark
}

\begin{abstract}
In this reflective paper, we examine the roles and attributes of the change agent in the context of the organisational innovation adoption process. Various skills and qualities are required and expected of such a role, however wit and humor are not among those qualities typically emphasized in the subject literature. Yet these may be essential ingredients in the successful management of change. We examine the role of humour in the workplace in particular, as an empowerment tool on one hand, and as a display of subversion on the other. We note that the traditional role and attributes of the court jester exude those very qualities that might be missing in traditional descriptions of the change agent: deep insight, wit, and the ability to exert strong influence through humor. We consider the notion of the corporate jester and discuss whether such a role may hold any merit for the process of change management.
\end{abstract}

\section{INTRODUCTION}

Jester wanted. Must be mirthful and prepared to work summer weekends. Must have own outfit (with bells). Bladder on stick provided if required.

The Times, August 5, 2004 
The above advertisement appeared on August 5, 2004, in the situations vacant section of The (London) Times newspaper. It was placed by English Heritage, a government-sponsored agency charged with the protection of historical buildings and monuments, and they were seeking a juggling, joke-telling, part-time entertainer for summer weekend events sponsored and promoted by them. Since no official "state jester" has been employed in the United Kingdom since Archie Armstrong, Jester to Charles I (a role Cromwell abolished in 1649 following Charles' execution), English Heritage claimed it as the first state jester appointment in England for more than 350 years.

The jester is thus by no means dead. In this theoretical and reflective paper, we review relevant research literature on the subject (drawing on the work of Ackoff [1993], Otto [2001] and Welsford [1935] in particular) to explore the role of the (corporate) jester as a change agent in organizational innovation in general, and technological change in particular. Ackoff first mooted the idea of the corporate jester in relation to change in the journal Systems Practice in 1993, but the paper is a short one and the idea is given limited development. Here we push the concept further as we consider the role of humor as a catalyst for diffusing the resistance that goes hand-inhand with uncertainty around the prospect of organizational change, especially where the implementation of new technology is involved. Although we will address the general role of humor, there will be a particular concern with the idea of the corporate jester. Lest confusion arise, we emphasize that in talking of such comedic figures, we do not in the first instance mean those informal clowns and buffoons that inhabit most workplace environments. Instead, we are primarily thinking of a kind of officially endorsed and empowered role that finds parallels in the appointed court jesters of medieval Europe and elsewhere. This being said, much of what we have to say applies to self-appointed folk figures as well as the formally sanctioned fool.

The subject of humor is gaining ground (as we shall see) as a worthy field of study amongst organizational scholars. There is a sporadic discourse on emotion within IS research, e.g., around anxiety and organizational learning (Wastell 1999, see below), and more recently on the influence of moods on understanding and action (Ciborra 2002). However, the topic of humor has not been specifically addressed (to our knowledge) in relation to the adoption and implementation of information technologies. Nonetheless, it is our general contention that technological innovation is essentially a process of organizational change, and so the topic of humor and the role of jesters are well worth considering within our domain. A simple technological example will feature in our reflections. We will discuss the role of the Microsoft paperclip as a kind of technological jester, albeit a jester that signally hinders rather than facilitates. While we have specific concerns for the information systems domain, nevertheless some of the messages here have general implications for the wider field of organizational studies and behavior.

In the next section, we will discuss some of the problems associated with change. In section 3 , we consider the generic role of the change agent, while in section 4 we raise the topic of humor in organizational settings. In section 5 , we return to the theme of the jester and the attributes required, and we consider the "virtual" jester made possible by technology. In the final section, we discuss implications for the management of change and technological innovation, along with our conclusions. 


\section{ANXIETY AND HUMOR IN ORGANIZATIONAL CHANGE}

The notion of business agility is one that evokes images of a firm with the capacity to embrace change quickly, and at short notice, for the express purpose of gaining or maintaining competitive advantage where firms might operate in such arenas. Other organizations, for example not-for-profit institutions such as local government agencies, may also have an interest in agility, although for different ideological motivations. Information technologies are seen by some as enablers of the change process, and are considered to be the very platform upon which business agility is predicated (Sambamurthy 2004). Business process reengineering (BPR) explicitly champions the potential of IT to effect revolutionary change in organizational structures and processes. Davenport (1993) speaks of process innovation in order to highlight the radical, transformational potency of IT. Despite this rhetoric, much IT-enabled change results in failure (Chang and Powell 1998; Wastell 1999). Software process innovation is a domain of special interest to IFIP WG8.6. Here the implementation of new tools and methodologies commonly evidences substantial resistance and frequent rejection (Hardgrave et al. 2003; Iivari 1996; Orlikowski 1993). The critical studies of Kautz and McMaster (1994) and Wastell (1996) provide telling insights into the problematics of methodological change, narrating the failure of two organizations to implement structured methods.

We contend that failed change efforts reflect a failure to "unfreeze" (Dent 1999; Lewin 1947), i.e., to abandon the old institutional order. Organizations seek to preserve their current identities, unless there a powerful reason to do otherwise. Threats and crises drive change. Gersick's (1991) notion of discontinuous change as punctuated equilibrium reflects the idea that the status quo will prevail in organizations unless there is a perceived need for change. Wastell et al. (2003), for instance, attribute the absence of a sense of urgent crisis as explaining the apparent resistance of local authorities in the United Kingdom to the modernizing imperatives of the eGovernment agenda. "Shocks" are required to overcome this organizational inertia: "only when people reach a threshold of sufficient dissatisfaction with existing conditions [will] they initiate action to resolve their dissatisfaction" (Van de Ven 1995). The notion of "problematization" within actor-network theory (Latour 1987) similarly reflects the need for innovations to align around a perceived sense of threat as the first critical stage in the process of technological innovation. McMaster et al. (1997) portray the rejection of a structured IS methodology in terms of the failure to "problematize" the situation in such a way as to portray the methodology as the accepted solution to the troubles and difficulties besetting the organization.

Extant organizational structures and processes provide members of business enterprises and other organizations with a sense of identity and security (Hirschhorn 1988; Menzies-Lyth 1988; Wastell 1999). Such psychological fortifications will not readily be given up. Hence the paradox that projects explicitly aimed at change often result in a perpetuation or indeed a strengthening of the status quo (Molinsky 1999). Change requires organizational energy (Benjamin 1993), with a strong collective sense of crisis serving to align and engage key stakeholder groups in the innovation process (Benjamin 1993; Latour 1987). Defensive reactions often occur (Wastell 1999; Wastell et al. 2003) when severe threats are confronted. The threat-rigidity hypothesis (Barnett 
and Pratt 2000) portrays a state of internal paralysis (strengthened internal control, restriction of information) elicited by crises that threaten to overwhelm the organization's repertoire of coping responses. Rigidity is one reaction to change, innovation is another. All forms of crises provide innovatory opportunities: to deal with problems, to unfreeze old behaviors, to develop new ways of understanding and acting (Kovoor-Misra et al. 2001).

The threat of change engenders unconscious processes within individuals (Bovey and Hede 2001) with these processes serving to provide protection from the feelings of anxiety that change evokes. These defenses can obstruct individuals from adapting to change, or they may function adaptively as part of a positive engagement with reality (Wastell 1999). Examples of negative defenses, such as denial, disassociation, projection, and acting out, are typically emphasized in psychodynamic accounts of change; however, there are positive defenses too. Humor is one such coping mechanism, which can help individuals embrace the need for change and to work through the anxieties it can produce. Bovey and Hede (2001) recently examined the relationship between humor and organizational change. In a survey of nine organizations undergoing major change efforts, they found humor to be associated with a "ready and willing" orientation to change. The maladaptive defenses, on the other hand, were associated with a resistive disposition.

In this paper, we develop the discourse on innovation and resistance by focusing on the psychological dynamics that underlie the process of organizational change. Since organizations continually shape (and are themselves in turn shaped by) social power relations, emotional and political forces are highly relevant in relation to the possibilities for, and defenses against change (Vince 1996). Specifically, we examine the role of humor as either a facilitative or a subversive agent. In particular, we will examine how humor might be expressed and realized in the workplace through the actions of agents of change. As Dyer (1984) noted two decades ago, change agent traits, including voice, appearance, and other physical and psychological attributes, will have consequences on the outcome of the implementation project

\section{THE CHANGE AGENT}

The role of the change agent is assumed to be critical to the successful implementation of new technologies (Rogers 1995). The change agent acts as a link between the change agency (those promoting the innovation), and the client system (the potential adopters of the innovation). As a professional protagonist, be it teacher, consultant, public health worker, development worker, or salesperson (ibid., pp. 336-370), the change agent thus occupies a privileged position in the process and the situation.

\subsection{Attributes of the Change Agent}

The term change agent has been in use since at least the early 1960s (Nielson 1961; Rogers 1962) and the role is deemed by many to be critical in the innovation-adoption? process. Despite this, there has been remarkably little research on the subject of change agents or of the qualities and attributes they might be expected to possess and exude. Detailed definitions, attributes, and descriptions tend therefore to be thin on the ground. 
Somewhat bizarrely, in two book with the phrase "change agent skills" in the titles (Egan 1988a, 1988b), no entry for "change agent" appears in the indexes. Nor does there appear to be any reference to the phrase in the books! Seemingly aimed at the inhouse practitioner, these books present models composed of prescriptive sequences of action that the author says companies need to implement if they seek and expect to attain successful change toward a notion of excellence. They are not specifically about change agents.

Eisenstein's wonderfully entitled The Printing Press as an Agent of Change: Communications and Cultural Transformations in Early-Modern Europe (1979) and Laver's Information Technology: Agent of Change (1989) similarly have no index entries for change agent. However, these two scholarly works at least have the respective merits of suggesting, if only in their titles, that change agents need not be limited to human beings but (consistently with actor-network theory) might just as easily be nonhuman.

Some attributes for change agents are inferred from the roles described by Rogers (1995, pp. 336-337), and these are that the change agent should

- possess "superior" technical knowledge of the innovation to that of client

- develop a need for change

- establish information exchanges

- diagnose problems

- create an intent to change

- translate that intent into action

- stabilize adoption (prevent discontinuance of the innovation)

- achieve a terminal relationship with the client (meaning that after adoption, he is no longer required)

Further insights are derived from other sources. For example, Clarke (1994) says that other functions of the change agent are

- to destabilize the status quo (before any organization can change, it must first be unfrozen from its current ingrained practices, as noted above)

- to induce a level of anxiety in the would-be adopter regarding the possibility of not changing that exceeds the natural increases in anxiety induced by the prospect of change: in other words creating the perception that the current ways are not working

- breaking rules; this is an essential part of innovation, and means heading in a direction that is quite opposite to that of everyone else

Turner et al. (1996), in discussing the project manager as change agent, require adoption of the roles of internal consultant, team leader, and ambassador. Dyer (1984) suggests the change agent might be called a facilitator, consultant, OD practitioner, or some other title, but that the essential qualities for success are leveling (honesty) and sharing (communicating) with the client. He adds that personality traits and voice and other physical attributes of the change agent will affect the change process, although exactly how and in what kinds of ways are not clear. 
In this paper, we broadly concur with Dawson (2003), who supports the claims of Buchanan and Story (1997), that the notion of a singular change agent role is ultimately flawed, as there are both multiple agents of change and multiple players who enter and are drawn into the political arena of change management. Moreover, in line with Bacharach and Baratz (1962), while certain explicit activities can be identified as political, these actions may only represent the tip of the political iceberg, for it is the decisions that are not made, the options that never arise, and the voices that are never heard that form an integral part of the political process, if not its primum mobile.

In short, all stakeholders in the system into which it is planned that change be introduced are strictly change agents and these will have an effect on the process. While this is so, we will be primarily concerned here with those individuals formally appointed to the role. They may be human or they may not be. But by whatever means the change agent is described in the literature, qualities that quite positively do NOT routinely emerge from the descriptions (yet may be critical for the successful implementation of change) are those of humor and wit.

\section{HUMOR AND ORGANIZATIONAL CHANGE}

Although the role of humor in organizational life is a neglected area, we have noted the recent upsurge in research on humor in organizational studies. The broad view that has emerged sees humor as essentially functional for the individual, i.e., that humor is used by individuals for a range of practical purposes (Thomas and al-Maskati 1997). The work of Kahn (1989) has been particularly influential in summarizing much previous research. Kahn identifies six principal functional roles for bumor in organizational settings (paraphrased from Thomas and al-Maskati).

- Coping. Humor enables people to detach themselves from potentially threatening situations, enabling them to maintain their self-image. Faced by collective threats, humor serves to generate cohesion within the group; laughing together forms an immediate social bond.

- Reframing. Humor allows people to separate themselves from dominant and conventional definitions of reality, constructed through prevailing power relations. By presenting alternative interpretations of situations, it becomes possible to envisage change to the status quo.

- Communicating. Humor enables painful or difficult messages to be conveyed in nonthreatening ways. Because humor has a frivolous face, serious messages that might have negative consequences for either or both parties may be transmitted safely.

- Expressing hostility. Humor may be used to express aggression, hinting indirectly at hostile feelings that would be inappropriate or dangerous to express openly. 
- Constructing identities. Humor can contribute to the formation of in-group culture, helping members to maintain their identities and their distinctiveness from others.

In general, Kahn contends that humor serves to enable individuals to manipulate psychological distance. Faced with an external threat, for example, humor helps individuals cope by both increasing the members' distance from the threat and by bringing members closer together. In organizational settings, humor thus enables members to deal with the ambiguous, uncertain, and political character of organizations as well as the tensions that arise from their engagement in alienating organizational systems.

Humor can certainly play a key role in facilitating organizational change. British Airways' much-publicized employment (see below) of a corporate jester provides a pertinent example (Westwood 2004). Another illustration is provided by the employment of a "humor consultant" by one firm to run staff workshops when they laid off 40 percent of their employees. The egregious claim is made that this device helped minimize the negative responses normally associated with downsizing (ibid). Overall, the published literature of whatever provenance tends to emphasize the pro-managerial virtues of humor, whether it be stimulating creativity, improving decision making, enhancing morale, improving group performance, or reinforcing corporate culture, Barsoux (1996), for instance, enthusiastically alludes to the "dividends of humor" as follows:

humor closes the communication gap between leaders and followers, it makes organizational confusion more bearable, it draws attention to areas in need of change, it facilitates change and encourages plurality of vision. In short, it breaks down barriers between people and makes an organization more participative and responsive. It follows that an environment which is amenable to humor will also facilitate organizational learning and renewal.

\section{CORPORATE JESTER AS CHANGE AGENT}

At the beginning of this paper, we referred to English Heritage and the advertisement it placed in The Times on August 5, 2004, along with the claims it made for the appointment being the first of its kind for over 350 years. Intriguing as such a claim sounds, it is, alas, untrue: English Heritage is hardly the "state" for one thing. As fanciful and unencumbered by the inconvenience of fact as this may be, it nonetheless did have the instant effect of attracting world-wide media attention. Subsequent coverage in articles in newspapers, magazines, and on television and radio stations across the globe was extensive. It was a very successful public relations exercise. Nonetheless and despite this, there are a number of professional jesters in civic and/or mayoral employment across the United Kingdom.

For example, Jonathan the Jester, awarded the title European Jester of the Year in 1999 by the UK's National Guild of Jesters, was appointed in 1997 as jester to the mayor (and thus the people) of Salisbury, a medieval town in Wiltshire, southwest England. His duties are to the communities of Salisbury, and to fund-raising for charitable causes. Other cities have also appointed official jesters. These include 
Sylvester the Jester of Leicester, ${ }^{1}$ Justin Andrews, jester to the city of Oxford, and Peterkin the Fool, to the city of Bristol.

The National Guild of Jesters, for which Jonathan the Jester currently holds the office of secretary and acts as its spokesperson, has over 30 full-time professional members. They estimate that there may be as many as 200 jesters currently working in England (many of these are talented part-time enthusiasts, including Nigel Roder, a.k.a. Kester the Jester, the successful candidate for the post advertised by English Heritage). In addition to the annual Titling Ceremony, the Guild organize frequent moots (convocations of jesters) in specific locations where they are happy to exercise their skills in return for a few jars of ale, and they act as an official voice for the disparate jester communities of England.

\subsection{The Corporate Jester}

There have been advocates for the appointment of corporate jesters for at least a decade-and-a-half (Ackoff 1993; Kets de Vries 1990), and real-life appointments of corporate jesters have indeed taken place. These include, for example, Paul Birch, appointed in 1994 as Corporate Jester to British Airways by Colin Marshall, former CEO of that organization, in order to "stir things up" (Sittenfeld 1998). Paul used his appointment to promote creativity, show managers that just because they were boss did not mean they were right, and to say the things that most people are generally afraid to say, at least publicly on record within their own organizations.

According to Ackoff (1993), the corporate Jester must be able to

- stimulate and disrupt the status quo

- recreate and provide the pauses that refresh the pursuit of change

- inspire creative transformations and help sustain them

- apply incisive and humorous revelations of the truth of their organizations and those who manage them

- ask questions that others dare not ask

- provide unexpected answers and be able to reject commonly held assumptions about their social systems

- seek power "to influence" rather than power "over" those who can bring about change

- express opinions authoritatively, based on acute observation and sound theory

- be corporate conscience, constructive critic, and thorn in the side of management through wit and humor

The role of the corporate jester is not dissimilar to that of the "sage fool" of older times. Such comic individuals exercised a check on kingly hubris by reminding the monarch of the transience of sublunary power and the fallibility of all human authority. Attention was drawn to the pursuit of foolhardy actions, offering the king a counter view

'For readers who may not know, Leicester is pronounced "Lester." 
to the sycophancy of fawning courtiers. As Kets de Vries (1990) has argued, the relationship of the corporate jester to organizational leadership is the same: to balance the hubris of the latter and engage with senior executives in an organizational drama dealing humanely and wisely with fundamental issues of human nature.

Shakespeare's fools provide familiar literary examples of the sage-fool genre. In a classic essay on the fool in King Lear, Knights (1959) observes that the fool "speaks to (and out of) a quite different order of apprehension; his function is to disturb with glimpses of confounding truths that elude rational definition." The comic garb of the fool's banter provides an obfuscating wrapping (another distancing device) around messages that, had they been directly delivered, risk bringing indignant wrath upon the head of the impertinent critic. The following exchange from the play provides a neat illustration:

Fool: The Lord that counseled thee to give away thy land, Come place him here by me, do thou for him stand:

The sweet and bitter fool will presently appear,

The one in motley here, the other found out there.

Lear: Does't thou call me fool boy?

Fool: All thy other titles thou hast given away; that thou was born with.

Kent: This is not altogether fool my lord.

Fool: No, faith, great lords and men will not let me; if I had a monopoly out, they would have part on't; and ladies too, they will not let me have all the fool to myself; they'll be snatching.

Unpalatable truths are imparted, but in a facetious, tangential manner that allows the fool to dance cleverly out of reach. A dangerous thing indeed to dub a king a fool, and the fool nimbly treads a dangerous line whilst pressing home his critique.

\subsection{Virtual Jesters?}

We earlier commented that change agents need not be human. Can we assume, then, the same of jesters? The answer is yes, and one that immediately springs to mind is Ronald McDonald, a virtual corporate clown who is as essential a trade mark to the McDonald Corporation as the large yellow " $M$ " that spans the globe.

Another of interest to us is the Microsoft paperclip, which combines some of the traditional attributes of the jester, namely wisdom (it guides us through our own ignorance to "correct" behavior) and humor. We have more to say about this virtual technological jester in the next section. 


\subsection{The Significance of the Jester in a Technology Setting}

Here we will again make analogies to the notion of a kingdom and the court jester. The kingdom is portrayed as the personal computer (PC), granting the user the role of the monarch. In the realm of the $\mathrm{PC}$, the court jester is portrayed as the Microsoft paperclip.

The objective of this exercise is to illustrate how the developers of the Microsoft office package have reinvented the formalized role of a teaser with the intention of making it a part of our daily work. The Microsoft paperclip accommodates many of the features which characterize the court jester, as noted above. Additionally, the paperclip purports to take the role of a change agent. The recommendations provided by the clip intend to help the user make better use of the software application, in the place of the normal tutorials where the user is in charge of when to get instruction on how to use the software application The paperclip activates itself when it assesses that the user can usefully benefit from getting advice on how to make the best use of the software.

Contrary to the sage fool and the corporate jester, it is dubious if the paperclip jester supports successful implementation, or if it is rather a hindrance. No challenge to the status quo is offered, no alternative realty held up to the user, although there is clearly an invitation to explore more of the dominant one provided by the application. Although there are traces of wisdom in the suggestions the Microsoft paperclip imparts to the user, most (if not all) users of the Microsoft office package known to the authors find the feature extremely annoying. They immediately choose the option "Hide" to avoid getting advice on how to make the best use of their software applications!

From this perspective, the efforts of IT jester as a change agent have failed. At the first possible chance, the user will discontinue the information exchange relationship, which is one of the first steps necessary in the process of supporting further acceptance of an innovation (Rogers 2003, p. 369). As an exercise in humorous change agency, it is an act, like an unfunny clown, that dies on its feet.

\subsection{The Jester as Change Agent}

It is arguable that jesters can operate as change agents, or at least that the two roles can learn from each other. In this section, we consider the respective qualities and characteristics further, through mapping the attributes of the change agent as described by Rogers (1995) and Clarke (1994) against the attributes of the corporate jester specified by Ackoff (1993). We include these in Table 1.

There are many general similarities and some significant differences in the attributes of each, although we would argue that those of the corporate jester represent a far richer, more human personification (apart from the fact and beside which they are a lot more fun!). By comparison, the picture that emerges of the change agent, especially as described by Rogers, is a somewhat dry and sober one, although Clarke's contributions introduce a far more radical element than would otherwise be the case.

It is when considering the difference phases of a change effort that the clearest differences emerge. Change involves questioning of the extant order, the envisaging of a new reality, followed by the technical work involved in building the new vision. It is 
Table 1. Attributes of the Change Agent and the Corporate Jester

\begin{tabular}{|l|l|}
\hline \multicolumn{1}{|c|}{ The Change Agent } & \multicolumn{1}{c|}{ The Corporate Jester } \\
\hline Destabilize the status quo (Clarke 1994) & Stimulate and disrupt the status quo \\
\hline Develop need for change (Rogers 1995) & $\begin{array}{l}\text { Recreate and provide the pauses that } \\
\text { refresh the pursuit of change }\end{array}$ \\
\hline $\begin{array}{l}\text { Create an intent to change (and) } \\
\text { translate that intent into action (Rogers } \\
\text { 1995) }\end{array}$ & $\begin{array}{l}\text { Inspire creative transformations and } \\
\text { help sustain them }\end{array}$ \\
\hline $\begin{array}{l}\text { Establish information exchanges } \\
\text { Rogers 1995) }\end{array}$ & $\begin{array}{l}\text { Apply incisive and humorous revela- } \\
\text { tions of the truth of their organizations } \\
\text { and those who manage them }\end{array}$ \\
\hline $\begin{array}{l}\text { Diagnose problems (Rogers 1995) } \\
\text { Break rules--essential for innovation: } \\
\text { else (Clarke 1994) }\end{array}$ & $\begin{array}{l}\text { Ask questions that others dare not ask } \\
\text { able to reject commonly held assump- } \\
\text { tions about their social systems }\end{array}$ \\
\hline $\begin{array}{l}\text { Achieve a terminal relationship with the } \\
\text { client (Rogers 1995) }\end{array}$ & $\begin{array}{l}\text { Seek power to influence rather than } \\
\text { power over those who can bring about } \\
\text { change }\end{array}$ \\
\hline $\begin{array}{l}\text { Superior technical knowledge (Rogers } \\
\text { 1995) }\end{array}$ & $\begin{array}{l}\text { Express opinions authoritatively, based } \\
\text { on acute observation and sound theory }\end{array}$ \\
\hline $\begin{array}{l}\text { Induce a level of anxiety in the would- } \\
\text { be adopter system related to not } \\
\text { changing (Clarke 1994) }\end{array}$ & $\begin{array}{l}\text { Be the corporate conscience, construc- } \\
\text { tive critic and thorn in the side of } \\
\text { management through wit and humor }\end{array}$ \\
\hline
\end{tabular}

the latter area where the roles most clearly diverge. The jester is not, par excellence, an implementer. His is not the mundane business of detailed plans, new management structures, targets, and deliverables - the quotidian banalities of project management. Doubtless comedic talents ease the fears and anxieties that surface during implementation, as we have argued above. But it is as critic and visionary where the jester most clearly scores, i.e., the use of humor to provoke debate and challenge the status quo.

\section{DISCUSSION AND CONCLUSIONS}

The role of the jester in human society appears to be one that is universally recognized and embraced by all cultures and in all times, a role that clearly has considerable social value and importance. Otto (2001) provides many anecdotal accounts of jesters from ancient Persia, from China, from the native peoples of the Americas and Australasia, plus the European court jester with which many of us are familiar. Welsford (1935), too, provides accounts of jesters from history, and fictional jesters from literature. Modern jesters have become stars of the cinema (e.g., Charlie Chaplin) or stand-up comedians. It can be no coincidence that three of the world's highest paid television 
personalities in recent times are successful jesters. Ray Romano is currently the highest paid TV star (Sibbald 2004). Before him, Kelsey Grammer held the title, he in turn succeeding Jerry Seinfeld.

The general thrust of academic as well as practitioner writing tends to promote a broadly benign view of organizational comedy. Its subversive side is seldom mentioned. Westwood (2004) addresses this seditious aspect, using the example of a corporate comedian to explore this darker role. Westwood's account stresses the limited prerogative of such hired jesters. Whether traditional jester or corporate comic, the fool presents an alternative reality, a different way of framing the prevailing situation. So much of humor works in this way; indeed, that is arguably its primary psychological dynamic, the questioning of the dominant reality, the status quo, by whatever comedic form it assumes: lampoonery, satire, farce, irony, slapstick. But herein lies its subversive limit. To work as humor, there must be relief after the tension, the discomfort created must be resolved, with a return to the dominant reality. For a moment, the veil is lifted, but normality must be restored if laughter is to erupt. Think of the clown gesticulating a gun at the circus audience. The gun is fired, and a flag pops out emblazoned with the word "Bang." Were the gun real and people killed, there would be no humor, only tragedy.

Writers such as Westwood thus contend that humor is inevitably and symbiotically contained by the dominant reality. Its subversive power is ever constrained. The corporate jester and the sage fool are hired hands, operating under the license of those in power. They cannot go too far in poking fun and challenging the authority on which they depend, biting the hand that feeds them. Lear's Fool well shows this, and by avoiding confrontation, he is ultimately impotent to deflect the King from the folly of his intended purpose. Equally, we would hardly expect Microsoft's paperclip to give the real advice some would say it should impart around the use of the company's products! The subversion of humor then, in Westwood's view, is exactly the opposite: it reinforces power relations rather than undermining them. The licensed banter of the fool only serves to remind the audience who is really in charge! Ironically, then, the prevailing hierarchy tends to be strengthened by comedic performance, however irreverent.

But is this always so? Can humor never be a weapon, a subversive agent? Where the fool is licensed, the humor sanctioned by the ruling group, this will surely be the normal outcome. But in conflictual situations, the articulation of an alternative reality and the attack on the status quo can undermine the dominant elite. Taylor and Bain (2003) reject the view that humor always contributes to organizational harmony. They describe the case of a call center where satire and joking not only served to provide relief from the routine of call center life, but contributed to the development of a vigorous counterculture that conflicted with corporate aims and priorities. A group of activists exploited humor to help make trade unionism a popular idea and to weaken managerial authority.

In conclusion, humor (and its formal embodiment in human or nonhuman jesters) plays an important role in human life. In organizational settings, although it may sometimes question the prevailing power relations and the dominant ontology, overall it is constrained in this critical function, tending inevitably to reinforce the status quo. Change agents invariably operate under the sanction and management of the existing hierarchy; their role is not to overturn the dominant regime. If change occurs, it is the 
transformation sought by the ruling clique. As an instrument of the established order, humor thus generally works to promote organizational harmony. In this role, it can clearly ease the dynamics of change, which is therapeutically valuable in these turbulent times emblematized by the agile business. The beneficial value of "fun at work" as a means of diffusing organizational stress is advocated by Redman and Mathews (2002), who recount the attempt of a major retail organization to instil such a "fun culture" (through humorous newsletters, fancy dress events). While some success is claimed, there are obvious cautions in looking to such crude attempts to manipulate culture in order to resolve deep-seated organizational malaise and realize sustainable improvements in performance. Nonetheless, the authors conclude that "the idea of the postmodern manager and the management consultant [i.e., the generic change agent role] as the corporate jester is not without its immediate appeal."

The natural state of any organization is that of autopoetic reproduction, which inevitably entails resistance to change (Porra 1990). As we noted above, organizations are held together by powerful forces which tend to maintain the status quo. The imperative to change inevitably evokes insecurity and stress, and humor can help allay the anxieties associated with innovation, overcoming the inertial forces embedded in the social defense structure of the organization, but at the same time creating a shared fund of cathartic stories to maintain social cohesion in times of stress and upheaval. Humor in organizations is above all a palliative, not a subversive force. In relation to technological change, this role is clearly manifest in the burgeoning corpus of computer jokes directed at an array of predictable targets. Searching the Internet with "jokes and Microsoft" as keywords yields (as might well be imagined) a good crop of mirthful images and verbal banter, in which the much-abused paperclip receives its deserved share of ridicule (e.g., the egregious offer of help to the writer of a suicide note!).

Humor thus provides a welcome distraction from the threats to jobs and security that are associated in the popular imagination with technological change. There is clearly a cathartic role for the jester (and humor in general) in easing the pain of change, although inept implementations (such as the paperclip) provide a cautionary tale. Innovators need also to be aware of the subversive role of humor to draw together and mobilize forces of resistance. This is a particular problem for our field where the widespread prevalence of spectacular IS failures provides a fecund source of humorous atrocity stories to be told with a wry, subversive edge. Humor though, in whatever form it might take, is a natural part of being human-enhancing joy, ameliorating pain, and building social bonds. It is a neglected area of study in our field, and one that would clearly benefit from further research (especially of an ethnographic character) to bring out the role humor plays (formally and informally) in facilitating or hindering change and innovation. By way of ending, we will give the final word to Thomas Sydenham, $17^{\text {th }}$ century physician and philosopher:

The arrival of a good clown exercises a more beneficial influence upon the health of a town than of twenty asses laden with drugs. 


\section{REFERENCES}

Ackoff, R. L. "The Corporate Jester," Systems Practice (6:4), 1993, pp. 333-334.

Bacharach P., and Baratz, M. "Two Faces of Power," American Political Science Review (56), 1962, pp. 641-651.

Barnett, C. K., and Pratt, M. "From Threat-Rigidity to Flexibility: Toward a Learning Model of Autogenic Crisis on Organizations," Joumal of Olganizational Change (13), 2000, pp. $74-88$.

Barsoux, J-L. "Why Organizations Need Humor," European Management Journal (14:5), 1996, pp. $500-508$

Benjamin, R. "Managing IT-Enabled Change" in Human Organizational and Social Dimensions of Information Systems Development, D. Avison, J. E. Kendall, and J. I. DeGross (Eds.), Ansterdam: North Holland, 1993, 381-298.

Bovey, W. H., and Hede, A. "Resistance to Organizational Change: The Role of Defense Mechanisms," Journal of Management Psychology (16:7), 2001, pp. 534-548.

Buchanan, D., and Story, J. "Role-Taking and Role-Switching in Organizational Change: The Four Pluralities" in Innovation, organizational change and Technology, I. McLoughlin and M. Harris (Eds.), London: International Thompson Business Press, 1997.

Chang, L-J., and Powell, P. "Towards a Framework for Business Process Re-Engineering in Small and Medium-Sized Enterprises," Information Systems Journal (8), 1998, pp.199-215.

Ciborra, C. The Labyrinths of Information: Challenging the Wisdom of Systems, Oxford: Oxford University Press, 2002.

Clarke, L. The Essence of Change, Upper Saddle River, NJ: Prentice Hall International, 1994.

Davenport, T. Process Innovation: Reengineering Work Through Information Technology, Boston: Harvard Business School Press, 1993.

Dawson, P. Reshaping Change: A Processual Perspective, London: Routledge, 2003.

Dent, E. B. "Challenging Resistance to Change," Journal of Applied Behavioral Science (35), 1999, pp. 25-41.

Dyer, W. G. Strategies for Managing Change, Reading, MA: Addison Wesley Publishing Company Inc., 1984.

Eisenstein, E. L. The Printing Press as an Agent of Change: Communications and Cultural Transformations in Early-Modem Europe (Volumes 1 and 2), Cambridge, UK: Cambridge University Press, 1979.

Egan, G. Change-Agent Skills A: Assessing and Designing Excellence, San Diego, CA: University Associates Inc., 1988a.

Egan, G. Change-Agent Skills B: Managing Innovation and Change, San Diego, CA: University Associates Inc., 1988b.

Gersick, C. "Revolutionary Change Theories: A Multi-Level Exploration of the Punctuated Equilibrium Paradigm," Academy of Management Review (16), 1991, pp. 10-36.

Hardgrave, B. C., Davis, F., and Riemenschneider, C. K. "Investigating Determinants of Software Developers' Intentions to Follow Methodologies," Joumal of Management Information Systems (20), 2003, pp. 123-151.

Hirschhorn, L. The Workplace Within: The Psychodynamics of Organizational Life, Boston: MIT Press, 1988.

livari, J. "Why Are CASE Tools Not Used?," Communications of the ACM (39:10), 1996, pp. 94-103.

Kahn, W. "Toward a Sense of Organizational Humor: Implications for Organizational Diagnosis and Change," The Journal of Applied Behavioral Science (25), 1989, pp. 25: 45-63.

Kautz, K., and McMaster, T. "The Failure to Introduce System Development Methods: A Factor-Based Analysis" in Diffusion, Transfer and Implementation of Information Technology, L. Levine (Ed..), Amsterdam: Elsevier/North-Holland, 1994, pp. 275-287. 
Kets de Vries, M. F. R. "The Organizational Fool: Balancing a Leader's Hubris," Human Relations (43:8), 1990, pp. 751-770.

Knights, L. C. Some Shakespearean Themes, Stanford, CA: Stanford University Press, and London: Chatto and Windus, Ltd., 1959.

Kovoor-Misra, S., Clair, J. A., and Bettenhausen, K. L. "Clarifying the Attributes of Organizational Crises," Technology Forecasting and Social Change (67), 2001, pp. 77-91.

Laver, M. Information Technology: Agent of Change, Cambridge, UK: Cambridge University Press, 1989.

Latour, B. Science in Action, Boston: Harvard University Press, 1987.

Lewin, K. "Frontiers in Group Dynamics," Human Relations (1:1), 1947, pp. 5-41.

McMaster, T., Vidgen, R., and Wastell, D. "Technology Transfer: Diffusion or Translation," in Facilitating Technology: Transfer. Through Partnership: Learning from Practice and Research, T. McMaster, E. Mumford, E. B. Swanson, B. Warboys, and D. Wastell (Eds.), London: Chapman and Hall, 1997, pp. 64-75.

Menzies-Lyth, I. Containing Anxiety in Institutions: Selected Essays, London: Free Association Books, 1988.

Molinsky, A. L. "Sanding Down the Edges: Paradoxical Impediments to Organizational Change," Journal of Applied Behavioral Science (35:1), 1999, pp. 8-24.

Nielson, J. The Change Agent and the Process of Change, Michigan State University, 1961.

Orlikowski, W. "CASE Tools as Organizational Change: Investigating Incremental and Radical Changes in System Development," MIS Quarterly (17:3), September 1993, pp. 309-340.

Otto, B. K. Fools Are Everywhere: The Court Jester Around the World, Chicago: University of Chicago Press, 2001.

Porra, J. "Colonial Systems," Information Systems Research (10:1), 1999, pp. 38-69.

Redman, T., and Mathews, B. P. "Managing Services: Should We Be Having Fun?" Services Industries Journal (22:3), 2002, pp. 51-62.

Rogers, E. M. Diffusion of Innovations, New York: The Free Press, 1962.

Rogers, E. M. Diffusion of Innovations ( $4^{\text {th }}$ ed.), New York: The Free Press, 1995.

Rogers, E. M. Diffusion of Innovations ( $5^{\text {th }} \mathrm{ed}$.), New York: The Free Press, 2003.

Sambamurthy, V. "IT as a Platform for Competitive Agility," in IT Innovation for Adaptability and Competitiveness, B. Fitzgerald and E. Wynne (Eds.), Boston: Kluwer Academic Publishing, 2004, pp. 467-468.

Sibbald, V. "Romano Wonders if Everyone Will Love Mooseport," Movie News, February 9, 2004.

Sittenfeld, C. "He's No Fool (But He Plays One Inside Companies)," Fast Company, November 19,1998, p. 66.

Taylor, P., and Bain, P. "Subterranean Worksick Blues: Humor as Subversion in Two Call Centres," Organization Studies (24:9), 2003, pp. 1487-1509.

Thomas, A. B., and Al-Mashati, H. "I Suppose You Think That's Funny! The Role of Humor in Corporate Learning Events," International Journal of Human Resource Management (8:4), 1997, pp. 519-538.

Turner, J. R., Grude, K. V., and Thurloway, L. (Eds.). The Project Manager as Change Agent, London: McGraw-Hill, 1996.

Van de Ven, A. H. "Managing the Process of Organizational Innovation" in Organizational Change and Redesign, G. Huber and W. Glick (Eds.), Oxford: Oxford University Press, 1995, pp. 269-294.

Vince, R. Managing Change: Reflections on Equality and Management Learning, Cambridge, UK: The Policy Press, 1996.

Wastell, D. G. "The Fetish of Technique: Methodology as a Social Defense," Information Systems Joumal (6:1), 1996. pp. 25-40. 
Wastell, D. G. "Learning Dysfunctions in Information Systems Development: Overcoming the Social Defenses with Transitional Objects," MIS Quarterly (23:4), December 1999, pp. 581600 .

Wastell, D., Kawalek, P., and Newman, M. "Plus ça Change: Defensive Translations and Resistance to IT-Enabled Change in Local Government" in Proceedings of the $11^{\text {th }}$ European Conference on Information Systems, M. Martinez, M. D. Marco, C. Ciborra, A. Carignani, and R. Mercurio (Eds.). Naples, Italy, 2003.

Welsford, E. The Fool: His Social and Literary History, London: Faber and Faber, 1935.

Westwood, R. "Comic Relief: Subversion and Catharsis in Organizational Comedic Theater," Organizational Studies (25:5), 2004, pp. 775-795

\section{ABOUT THE AUTHORS}

Tom McMaster is a lecturer in the Information Systems Institute in the University of Salford, Manchester, UK. Tom has a variety of research interests including technology transfer. $\mathrm{He}$ is a member of IFIP 8.2 and a founding member of IFIP 8.6, for which he co-organized the 1997 Ambelside event. Tom can be reached at t.mcmaster@salford.ac.uk.

David Wastell is Professor of Information Systems at Nottingham Business School. His current research interests are IT-enabled innovation, public sector reform and electronic government, and the human factors design of complex systems. He has published over 100 journal articles and conference papers in information systems, human factors, and health informatics, after an early research career in cognitive and clinical psychophysiology. He is on the editorial board of the European Journal of Information Systems and Information and Management and has co-organized two IFIP conferences (WG 8.6 in 1997 and WG 8.2 in 2004). Dave has considerable consultancy experience, especially in the public sector. He can be reached at dave_wastell@hotmail.com

Helle Zinner Henriksen is an assistant professor in the Department of Informatics at the Copenhagen Business School. She has an M.Sc. in law from the University of Copenhagen and a Ph.D. from the Department of Informatics at the Copenhagen Business School. Her Ph.D. is in the field of Management Information Systems with particular interest in the implications of institutional intervention with respect to interorganizational adoption and diffusion. Her research interests include adoption and diffusion of IT in the private and public sectors. Her most recent work is focused on eGovernment and regulation of eGovemment. Helle is involved in the Center for Electronic Commerce and the Center for Research on IT in Policy Organizations, both at the Copenhagen Business School. More details on her research activities and publications can be found at http://web.cbs.dk/staff/hzh/. Helle can be reached at hzh@inf.cbs.dk. 